\title{
SISTEMA TOYOTA DE PRODUÇÃO - STP: SUGESTÃO PARA ADOÇÃO DA FILOSOFIA ÀS EMPRESAS DO SETOR ELÉTRICO BRASILEIRO
}

\author{
TOYOTA PRODUCTION SYSTEM - TPS: SUGGESTION FOR COMPANIES \\ IN THE BRAZILIAN ELECTRIC SECTOR TO ADOPT THIS PHILOSOPHY
}

\author{
José Rubens dos Santos 1 \\ http://lattes.cnpq.br/0701602751042272 \\ https://orcid.org/0000-0002-5088-4698 \\ Indira Mara Santos 2 \\ http://lattes.cnpq.br/ 7870713020420740 \\ https://orcid.org/0000-0003-0381-9145
}

Recebido em 16 de setembro de 2019

Aprovado em 21 de janeiro de 2020.

\begin{abstract}
RESUMO: Este trabalho visa avaliar o índice de utilização das ferramentas do Sistema Toyota de Produção - STP, bem como identificar pontos impeditivos do desenvolvimento deste nas áreas de logísticas de apoio à geração, transmissão e distribuição de energia elétrica no Brasil, objetivando, através de evidências reais, propor os princípios do STP como modelo na gestão destas áreas para as empresas do setor elétrico brasileiro. Para tanto, utilizou-se o método de pesquisa de estratégia do tipo survey com técnica de coleta de dados utilizados através de questionários, onde em um universo de 291 empresas, tirou-se uma amostra de 33 das principais empresas dos três seguimentos do setor elétrico brasileiro. Após a coleta dos dados, estes foram plotados em planilhas utilizando o software Excel para geração de gráficos que pudessem facilitar o entendimento do objeto de pesquisa, assim como analisar a situação das empresas estudadas e propor o modelo com base no STP. Os resultados da pesquisa revelaram que todas as empresas se encontram distante do modelo de gestão praticado pelo STP e, como conclusão sugere-se a aplicação da filosofia e dos princípios de gestão às empresas do setor.
\end{abstract}

Palavra-chave: Sistema Toyota de Produção. Gestão Empresarial. Energia elétrica

\begin{abstract}
This paper aims to evaluate the utilization of the Toyota Production System (TPS) tools in the generation, transmission, logistics and distribution of electric energy in Brazil, identifying obstructions to its development, proposing the TPS principles as a model in the management for companies in the Brazilian electricity sector. To do so, it was used the survey research strategy method with data collection used through questionnaires where, in a universe of 291 companies, a sample of 33 of the main companies of the three segments of the Brazilian electric sector was pulled off. After the data collection, these were plotted in spreadsheets using Excel to generate graphs that could facilitate the
\end{abstract}

${ }^{1}$ Meste em Gestão Empresarial pela Universidade Lusófona de Humanidades e Tecnologias (2018). MBA em Administração pela FGV-Brasil. Graduado em Administração de Empresas pela UNDB. E-mail: jrubensdossantos@gmail.com

2 Mestrado (2016) e Doutoranda (previsão para 2021) em Comércio Internacional/Economia - Huazhong University of Science and Tecjnology - Wuhan, China. Graduação em Administração - Unidade de Ensino Dom Bosco (2008). Graduação em Turismo pela Faculdade Atenas Maranhense (2006). E-mail: santos.indira@gmail.com 
understanding of the research object, as well as to analyze the situation of the companies studied and propose the model based on the TPS. The results of the research revealed that all companies are far from the management model practiced by TPS and, as a conclusion, the application of the philosophy and management principles to companies in the sector is suggested.

Keyword: Toyota Production System. Business Management. Electric Power

\section{INTRODUÇÃO}

A energia no Brasil, de forma genérica, é de fato um produto caro; a energia elétrica em suas diversas formas: hidro, térmicas, eólicas e solar; Petróleo e seus derivados, gás natural etc. Os altos preços são resultados de três fatores: 1 - Elevados custos operacionais; 2 - Pesadas taxas de desenvolvimento do setor associada a carga tributária (Estruturante e não estruturante) (PIZETA, 2009 and D'ARAUJO, 2009); 3 - o modelo de privatização adotado pelos governos socialistas (2002 à 2016) com extremo teor protecionista. Este último traz em seu bojo um nível de proteção tal aos empresários do setor que inibe o desenvolvimento de novas tecnologias que privilegie as reduções dos preços finais aos consumidores.

Observemos que entre os anos de 2014 a 2018 as tarifas de energia elétrica acumularam 44\%, segundo LIS (2018); para a GLOBAL-RATES (2019), a inflação foi de 33,87\%; a AUDITEC (2019), o salário mínimo cresceu 37,83\%. Políticas desta natureza provocam distorções na economia de forma geral. A produção industrial sofre impondo limitação na produção, cortando postos de trabalho e majorando preços; a população, com o descompasso entre ajuste salarial versus tarifas públicas; bem como o governo, pois este é um importante consumidor do produto. Tudo isso provoca pressões sobre a inflação, que por sua vez recebe mudanças metodológicas ao sabor de cada governo ou conjuntura. Neste sentido, a energia elétrica no Brasil caracteriza-se como a mais cara do mundo, como afirma Chuahy e Victer (2002), e este é um problema histórico no país, pois já na década de 1930, segundo Netto (2013), o governo do Presidente Getúlio Vargas criou políticas para o desenvolvimento do setor elétrico com a criação da maioria das taxas e impostos incidentes no setor. No entanto, mesmo com o desenvolvimento do setor e da economia como um todo, os governos que o sucederam não provocaram ajuste redutivo nestas.

Em meio a esse clima de euforia, os governos e a cadeia ligada aos serviços públicos ignoram completamente modelos modernos de gestão já consagrados que privilegiam a redução sistemática de desperdícios, de modo a transferir ao consumidor final tal benefício, como o Sistema Toyota de Produção, STP, hoje mais conhecido como Produção Enxuta - PE. Nesta perspectiva, há a necessidade de modernizar as gestões logísticas de apoio a geração, transmissão e distribuição, passando por pessoas e processos.

Este artigo é um recorte da Dissertação de Mestrado, sob o título: "Princípios de Gestão do Sistema Toyota de Produção: proposta para aplicação em uma usina de geração de energia elétrica no norte do Brasil". O objetivo deste Artigo é propor o STP/PE como modelo de gestão a uma grande usina hidroelétrica instalada na Cidade de Porto Velho, Estado de Rondônia, norte do Brasil, e sugeri a aplicação destes princípios a todas as empresas do setor. A Pesquisa teve abrangência nacional em 18 Estados brasileiros, o que representa 66,66\% dos entes federados, onde em um universo de 291 empresas, selecionou as 33 mais relevantes do setor e foi realizada no ano de 2014. 


\section{O SETOR ELÉTRICO BRASILEIRO - SEB: DE SUAS GÊNESIS À ATU- ALIDADE}

O SEB hoje, no Brasil, apresenta os mesmos sintomas da década de 1930, quando Eduardo Guinle escreveu o Artigo no Jornal do Commércio intitulado "A Light e seus negócios da China”, no qual denunciava os abusos tarifários praticados pelas concessionárias. Nesta época, vigorava a liberdade tarifária que era reajustada com base na cláusula ouro, ou seja, o reajuste baseava-se na variação da cotação do ouro. Para Chuahy e Victer (2002), este modelo garantia ao investidor um pleno equilíbrio econômico-financeiro. Nesta perspectiva, o modelo de concessões implantado pelo governo brasileiro, na primeira década de 2000, criou todas as condições para retornarmos aos primórdios da criação do setor. A diferença é que atualmente existe a Agência de Energia Elétrica - ANEEL, que gerencia o sistema e ratifica os fabulosos reajustes do setor. Para Monteiro e Santos (2010), em um ambiente como este, com a duplicidade funcional da energia, ou seja, atender aos objetivos sociais e ao mesmo tempo interesses políticos, faz com que as discursões ideológicas de natureza política ganhem força. Este argumento também é defendido por Savóia (2009), pois para ele, este quadro é resultado do nacionalsocialismo que criou todas as condições para a forte ingerência política que sofre o setor.

\section{O SEB E OS DESAFIOS}

O setor elétrico configura-se como um dos mais dinâmicos setores da economia brasileira, ao lado dos setores bancário e de telecomunicações. O SEB é bem diversificado, tendo em sua matriz produções hídrica, térmicas (nuclear, diesel, gás, óleo etc.), eólica, fotovoltaica, como demonstrado no gráfico 1. A hidroeletricidade lidera a produção representando cerca de $65 \%$ da produção de eletricidade do país e é fonte com menor grau de decisão de geração em função de depender de ciclos hidrológicos. A termoeletricidade gera energia elétrica a partir de um combustível (em geral, fóssil) que gera calor, para através da pressão de vapor sobre uma turbina, acionar um gerador elétrico. Este se caracteriza, portanto, pelo controle pleno que se tem sobre a decisão de geração, por não dependerem de ciclos naturais (hidrológico, vento, sol etc.). Por outro lado, esta fonte de energia, no caso brasileiro, atua como uma garantia complementar do sistema (D'Araujo, 2009). 
Gráfico 1 - Matriz da energia e fonte de geração

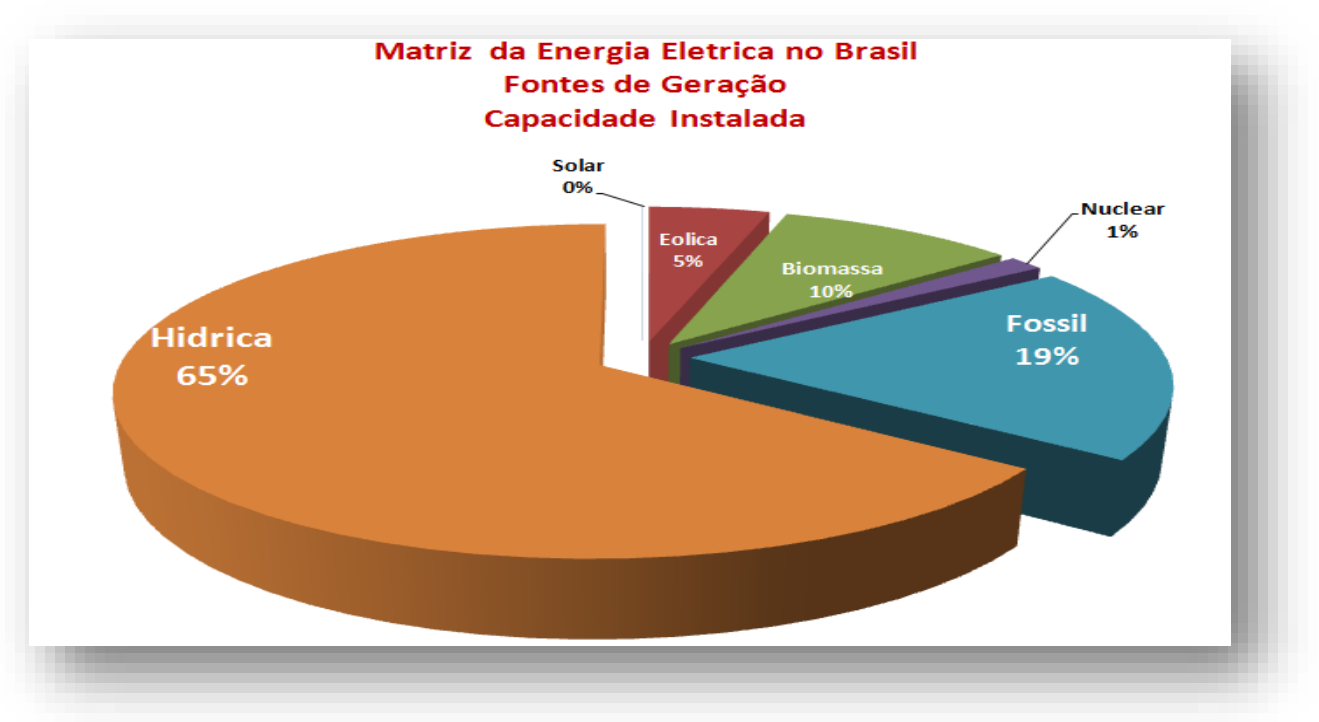

Fonte: Elaborado pelos autores com dados do ONS.

Os desafios não são poucos. Podemos listar os logísticos, as regulamentações ambientais, o financiamento do setor para expansão da oferta do produto, a necessidade de redução da carga tributária, bem como mudanças com modernas técnicas de gestão necessárias para uma melhor eficiência. Em 2013, o governo brasileiro, através da ANEEL, promoveu uma Revisão Tarifária Extraordinária, através da Lei no 12.783/2013. Esta revisão focou nos encargos setoriais e nos tributos incidentes sobre a energia elétrica. Segundo Fachini (2015), todo benefício desta medida, ou seja, 28,2\% foram imediatamente suprimidas com reajuste de tarifa sob a justificativa de elevação de custos pelas concessionárias.

O Instituto Acende, no que se refere ao financiamento do SEB, analisando o relatório anual do World Bank Group 2016ª , avalia que o país não dispõe de uma legislação integrada e unificada que trate da questão de forma sistemática com a regulamentação das garantias muito limitadas, o que fragiliza os direitos dos credores e dificulta a concessão de crédito.

Por outro lado, o incentivo a utilização de técnicas administrativas modernas, já consagradas mundialmente, é urgente. Para Arantes (1994), os novos paradigmas existentes nos modelos de gestão em termos de mudança e conhecimento tem mudado a forma de pensar de diretores e gerentes, uma vez que as organizações vivem em constante evolução de seus sistemas e consequentemente exigindo uma nova postura nos estilos pessoais e gerenciais que devem convergir para uma realidade diferenciada e emergente nos dias atuais. Cordeiro e Ribeiro (2002) destacam que o grande desafio desta última década vem sendo a capacidade e a competência diária que as organizações enfrentam para se adaptarem e levarem a todos os seus níveis hierárquicos e funcionais, da alta gerência ao piso de fábrica, a incorporação de novos modelos, métodos, técnicas, instrumentos, atitudes e comportamentos necessários a mudanças, inovações e a sobrevivência sadia e competitiva no mercado. Estes ainda enfatizam que em todas as partes há a percepção clara das transformações, seja pelas mudanças introduzidas internamente pela reengenharia, como a descentralização, o empowerment ou a terceirização, seja pelas transformações no cenário externo, como o declínio de antigas empresas multinacionais e o surgimento de novos competidores, o administrador de empresas enfrenta desafios totalmente novos. 


\section{O STP/PE}

O Pensamento Enxuto é uma filosofia de produção que traz consigo elementos do STP. Para muitos pensadores, o primeiro é uma evolução do segundo, tendo em vista que, originalmente, este último, destina-se a manufatura. Já o primeiro, num contexto mais amplo, abraça todos os segmentos da economia, sobretudo, o setor de serviços. Neste sentido, enquanto o segundo cuida da produção material, tangível e de média a longa pericibilidade, o primeiro abraça, também, o produto intangível e altíssima pericibilidade.

Santos (2003) defende que com a atual conjuntura de mercados, o alcance da competitividade torna o PE um imperativo, do qual as organizações não podem abdicar.

Antunes et al (2008) coloca esta evolução como algo absolutamente natural e lembra num contexto histórico as revoluções pelas quais os sistemas de produção passaram até chegar ao PE.

Taiichi Ohno (1997) resume o PE em uma frase simples: "forma de se fazer cada vez mais com cada vez menos". Indo além, ele acrescenta: "é uma forma de especificar valor, alinhar na melhor sequência as ações que criam valor, fazer com que as atividades se interrompam quando solicitada e realizar da forma mais eficaz". Ele enfatiza que o objetivo do STP mais importante é aumentar os efeitos da produção pela eliminação completa dos desperdícios. Levy (1997) destaca como principais características da PE: a flexibilidade na produção; as entregas, através do JIT; os estoques reduzidos; defeito zero e, a integração na cadeia de fornecedores. Para Santos (2003), as principais caracteriza do STP/PE são: A Estabilidade e comprometimento, o poder de decisão, a hierarquia, o trabalho em equipe, a garantia para o fornecedor.

\section{PRINCÍPIOS DO STP/PE}

Womack e Jones (1998), em A Mentalidade Enxuta nas Empresas, definiram os cinco princípios que norteiam o PE, como sendo: Valor, A cadeia de valor, Fluxo Contínuo, Fluxo Balanceado, Produção Puxada e Perfeição ou Melhoria Contínua. Estes princípios foram constantemente explorados nas obras do mesmo autor: "A máquina que mudou o mundo" e são sempre referendados por renomados estudiosos do tema. Entretanto, os princípios a seguir estão substanciados no que ficou denominado como Just In Time - JIT, ou conjunto de técnicas que sustentam o STP/PE.

\section{Valor}

Valor sempre será aquilo que o cliente considera como compensação pelo seu tempo, esforço e investimento, sendo a diretriz fundamental de qualquer sistema verdadeiramente enxuto voltado a criar e desenvolver estratégias competitivas de valor superior sob a ótica do cliente. (OHNO, 1997; WOLMACK E JONES, 1998; MORGAN E LIKER, 2008; PINTO, 2009; BYRNE, 2014);

\section{Fluxo Contínuo e Fluxo Balanceado}

O fluxo como princípio do PE tem duas vertentes. O fluxo como processo genérico, ou 
seja, Fluxo contínuo e o Fluxo balanceado que é uma ferramenta do STP e que neste momento tornam-se complementares. Para Womack e Jones (1998), o fluxo entra em cena no momento em que a empresa já conta com o valor para o cliente definido, bem como sua cadeia de valor totalmente mapeada e personalizada e as etapas que geram desperdícios eliminadas;

\section{Produção Puxada}

A produção puxada ou Jus In Time - JIT está intimamente relacionada com a produção por demanda, ou seja, vende-se o produto para depois efetuar aquisições das matérias-primas e posteriormente produzir, montar, transportar, entregar. Nas organizações com este modelo produtivo, observa-se o mínimo de estoque de matéria-prima, apenas o suficiente para poucas horas de produção. Esta dinâmica exige um número reduzido de fornecedores, os quais devem ser treinados e instruídos a efetuarem entregas programadas;

\section{Melhoria contínua}

Para Ohno (1997) Womack e Jones (1998), a melhoria contínua, como último princípio do PE é traduzida como a expressão japonesa denominada KAIZEN, que é uma técnica do conceito do JIT cujo objetivo é a melhoria contínua do processo, permitindo que a empresa tenha menores custos e maiores lucros, sendo mais competitiva nos setores que atuam. Para Buttner (2008), ela deve ser encarada como uma filosofia de vida, devendo ser aplicada não somente no ambiente profissional, como em nossa vida pessoal e familiar. O autor destaca como sendo cinco os principais elementos da Melhoria Contínua: Qualidade em tudo que faz; Esforço e dedicação; Envolvimento de todos; Vontade de mudar e de vencer, e Comprometimento. PINTO (2009) e MONDEN (2015), no entanto, defendem o incentivo dela em todos os seus níveis departamentais, ouvindo constantemente o cliente e procurando ser rápido em suas demandas, solucionando conflitos entre produtividade e fatores humanos, pois suas atividades ajudam a reduzir equipes e a elevar o moral dos trabalhadores. Spears e Bowen (1999) afirmam, interpretando Taiichi Ohno, que o ideal do STP/PE será o momento em que um cliente estacione seu carro, efetue um pedido no balcão de um produto ou serviço personalizado e recebêlo imediatamente ao menor preço possível e sem defeitos. Enquanto não se chega a este ideal, os autores sugerem que tais deficiências constituem-se numa constante fonte de tensão criativa para futuro esforços de melhorias.

\section{METOdologia}

Metodologia é, segundo Rodrigues (2007), um conjunto de abordagens, técnicas e processos utilizados pela ciência para formular e resolver problemas de aquisição objetiva do conhecimento de uma maneira sistemática.

A pesquisa adotou uma abordagem de natureza quali-quantitativa, em duas etapas, com utilização do método levantamento para obtenção dos dados. Para Vergara (2003), por apresentar valores numéricos, sendo quantificável, a pesquisa é quantitativa e por envolver interpretação de textos, resultados estatísticos, modelos de gestão, a pesquisa é qualitativa. Desta forma caracterizamos sua abordagem da situação-problema.

Da ótica dos objetivos, a pesquisa caracterizou-se como descritiva-explicativa. Enquanto 
para Rodrigues (2007) a pesquisa descritiva são fatos observados, registrados, analisados, classificados e interpretados, sem interferência do pesquisador, com uso de técnicas padronizadas de coleta de dados (questionário e observação sistemática), para Vergara (2003), uma das principais características deste método é o não compromisso em explicar os fenômenos que descreve. Neste sentido, Rodrigues (2007) observa que pesquisa explicativa identifica fatores determinantes para a ocorrência dos fenômenos. Exemplos: nas ciências naturais o método aplicado é experimental; ciências sociais o método observacional, o que Vergara (2003) simplesmente considera como tornar inteligível.

\section{INSTRUMENTO DE COLETA}

O instrumento de coleta dos dados escolhido, por ser uma pesquisa quali-quantitativa, foi a aplicação de um questionário estruturado com 51 questões objetivas de múltipla escolha, no qual das questões 23 a 51 utilizamos a escala de Likert com cinco pontas para medir os parâmetros, apresentados aos gestores das áreas das organizações do setor informadas. O questionário teve como parâmetro o construto desenvolvido por Sellito et al (2003), no qual os autores desenvolveram uma metodologia para determinar o grau de preparação para a indústria de serviços para receber o PE., trabalho que objetou investigar a compreensão do termo teórico "mentalidade enxuta" na indústria de transporte coletivo de Porto Alegre, usando como parâmetro os cinco princípios da PE de Womack (1998). Os cinco princípios transformaram-se em cinco construtos com seis variáveis manifestas categóricas nominais. Para mensuração, utilizamos nos construtos do questionário a escala Likert de cinco pontas, com os seguintes dados: Nenhum, pouco, razoável, muito e profundo.

Para Llauradó (2010), a escala Likert é um instrumento de resposta psicométrica, que nos permite medir as atitudes e conhecer o grau de conformidade do entrevistado com qualquer afirmação proposta, ou seja, é uma medida objetiva e estandardizada de amostras do comportamento das pessoas, habitualmente usada em questionários, por enfatizar as aptidões individuais dos respondentes. Para Doane e Seward (2014), a robustez desta escala é definida pelo número de pontos, geralmente entre 5 e 7 , o que nos permitiu a comparações entre os segmentos do setor e energia de âmbito nacional, objetivando determinar melhores práticas, suas virtudes e dificuldades de implantação e manutenção.

\section{UNIVERSO DA PESQUISA}

A amostra foi obtida utilizando uma pesquisa bibliográfica, de âmbito Nacional, tendo participado 18 Estados (66,66\%), onde em um universo de 291 empresas, selecionou as 33 mais relevantes do setor, e a pesquisa foi realizada ao longo do ano de 2014.

As empresas selecionadas representam: 59,34\% do setor de Geração de energia, 54,77\% da Distribuição e 69,16\% de Transmissão, sendo que 72,73\% de controle estatal e 27,27\% privado.

\section{ANÁLISES DOS RESULTADOS}

Para Junior e Costa (2014), a mensuração é um dos meios pelos quais são acessados e descritos os dados para compreender os fatos e fenômenos de interesse, sendo, desta forma, uma 
questão presente em todas as ciências.

Os resultados obtidos foram analisados sendo utilizados recursos, tais como: gráficos, tabelas, entre outros, e utilizamos como instrumento de pesquisa e mensuração dos dados a escala Likert de cinco pontas. As análises dos resultados da pesquisa foram realizadas com os modelos estatísticos envolvendo: Alfa de Cronbach, Teste de igualdade de duas proporções, P-valor, Coeficiente de variação, Intervalo de confiança; Média e mediana, entre outros, e utilizados os softwares: SPSS V17, Minitab 16 e Excel Office 2010.

O Alfa de Cronbach é um método utilizado para verificar a consistência interna dos dados, o que significa o grau de confiabilidade. Para Hair Jr et al (2005), confiabilidade é o grau que um conjunto de indicadores de uma variável latente é consistente em sua mensuração. Para Araujo e Laburu (2009), o Coeficiente de confiabilidade é um indicador da precisão das pontuações observadas dos sujeitos investigados por procedimentos empíricos. Para Hora, Monteiro Et al (2010), o alfa é calculado a partir da variância dos itens individuais e da variância das somas de cada avaliador. Este método tem sido bastante usado para estimar a confiabilidade de instrumentos de medida (CRONBACH,1951).

A fórmula para o cálculo é dada por:

$r=\frac{n}{n-1}\left(1-\frac{\sum \sigma_{1}^{2}}{\sigma_{\text {sum }}^{2}}\right)$, onde: $\sigma_{i}^{2}$ é a variabilidade dos itens e $\sigma_{\text {sum }}^{2}$ é a variabilidade total.

Esta estatística tem uma escala de 0 a 1 e quanto maior o seu valor, maior é a consistência interna dos dados.

O Teste de Igualdade de duas Proporções é um teste não paramétrico que compara se a proporção de respostas de duas determinadas variáveis e/ou seus níveis é estatisticamente significante. Assim, trabalhamos com as seguintes hipóteses:

$$
\left\{\begin{array}{l}
H_{0}: \mathrm{p}_{1}=p_{2} \\
H_{1}: \mathrm{p}_{1} \neq p_{2}
\end{array}\right.
$$

Para realizarmos este teste devemos calcular: $f_{1}, f_{2}$ e $\hat{p}$

$$
\begin{aligned}
& f_{1}=\frac{x_{1}}{n_{1}}, \\
& f_{2}=\frac{x_{2}}{n_{2}}, \mathrm{e} \\
& \hat{p}=\frac{x_{1}+x_{2}}{n_{1}+n_{2}} .
\end{aligned}
$$

Com isso, podemos agora calcular a estatística teste. 


$$
\begin{gathered}
Z_{c a l}=\frac{f_{1}-f_{2}}{\sqrt{\hat{p}(1-\hat{p})\left(\frac{1}{n_{1}}+\frac{1}{n_{2}}\right)}} \\
- \text { Se }-Z_{\frac{\alpha}{2}} \leq Z_{c a l} \leq Z_{\frac{\alpha}{2}},
\end{gathered}
$$

não se pode rejeitar $H_{0}$, isto é, a um determinado risco $\alpha$. Dizemos que não existe diferença entre as proporções.

$$
\text { - Se } Z_{c a l}>Z_{\frac{\alpha}{2}} \text { ou } Z_{c a l}<-Z_{\frac{\alpha}{2}}
$$

rejeita-se $H_{0}$, concluindo-se, com risco $\alpha$, que há diferença entre as proporções.

Para Kuiper's (1988), Um p-value é uma medida de quanta evidência você tem contra a hipótese nula. Quanto menor o p-value, mais evidência você tem. Caso esse valor seja maior que o nível de significância adotado (erro ou $\alpha$ ), concluímos, portanto, que a $H_{0}$ (a hipótese nula) é a hipótese verdadeira, caso contrário ficamos com $H_{1}$, a hipótese alternativa.

De acordo com Rosa (2011), O teste t para uma amostra é aplicado quando se deseja testar a hipótese de que a média da população $(\mu)$ é igual a um hipotético valor:

$$
\mu 0 . \mathrm{HO}: \mu=\mu 0 \mathrm{H} 1: \mu \sigma=\mu 0 \text { ou } \mu<\mu 0 \text { ou } \mu>\mu 0
$$

Em estatística, média e mediana são medidas de posição. Média é o centro da distribuição dos dados sendo muito sensível a grandes ou pequenos valores, pois é uma medida pouco resistente. Por sua vez, a mediana divide a amostra ao meio, ou seja, que 50\% dos indivíduos estão acima do valor da mediana e 50\% abaixo. Esta é uma estatística analisada em relação à média, pois quanto mais próximo seu valor for em relação à média, mais simétrica será a distribuição e uma distribuição assimétrica possui uma grande variabilidade com certeza.

A variabilidade é media pelo desvio padrão. Quanto mais próximo (ou maior) esse valor for em relação à média, maior será a variabilidade, o que é ruim, pois assim não teremos uma homogeneidade dos dados.

O Coeficiente de variação - CV É uma estatística que avalia o quanto a variabilidade representa da média. O ideal é que este índice seja o mais baixo possível $(<50 \%)$, pois desta forma, teremos uma baixa variabilidade e consequentemente uma homogeneidade dos resultados.

Os valores mínimo e máximo são respectivamente o menor e o maior valor encontrado na amostra, não tem nada a ver com mais ou menos um desvio padrão.

Os quartis são descritivos de posição, ou seja, não são influenciadas por valores extremos (como a média e desvio padrão). O $1^{\circ}$ quartil (Q1) nos mostra a distribuição até $25 \%$ da amostra e o $3^{\circ}$ quartil (Q3) mostra a distribuição até 75\% da amostra.

O intervalo de confiança (IC) ora somado e ora subtraído da média, nos mostra a variação da média segundo uma probabilidade estatística. Também aqui, esses limites não têm nada a ver com o cálculo de mais ou menos um desvio padrão em relação à média. Lembrando que o IC é mais confiável, pois temos uma probabilidade estatística associada em seu cálculo.

A ANOVA é usada na comparação entre os cinco segmentos e os dois controladores foram 
utilizados no teste paramétrico ANOVA, ou análise de variância. Para SOUZA (2015), A ANOVA utilizando variáveis contínuas permite que vários grupos sejam comparados a um só tempo, e, por o teste ser paramétrico, os grupos têm que ser independentes. Nesta perspectiva, o p-valor é a probabilidade, sob H0, de ocorrência do valor particular observado para a estatística de teste ou de valores mais extremos. A probabilidade de significância de um teste mede a força da evidência contra $\mathrm{H} 0$ em uma escala numérica. Um p-valor pequeno indica uma forte justificativa (evidência) para a rejeição de H0. Para Shikamura (2005), a ANOVA basicamente divide a variabilidade em variabilidade Entre Grupos e variabilidade Dentro de Grupos e compara as duas. Quanto maior for a primeira comparada à segunda, maior é a evidência de que existe variabilidade entre grupos.

\section{OS RESPONDENTES}

A indicação dos profissionais respondentes foi prerrogativa direta da direção de cada empresa nos setores de Logística, Suprimentos, Almoxarifado e Serviços Gerais, sendo os profissionais: Gerentes, Supervisores, Coordenadores, Analistas e operadores.

O resultado da pesquisa indicou uma massa de profissionais que se caracterizam por serem do sexo masculino, alto grau de escolaridades, jovens e por bom tempo de atuação profissional: 79,61\% ser do sexo masculino; 70,87\% estar na faixa etária dos 40 anos; 55,34\% ter alto grau de escolaridade, ou seja, pós graduação; 44,66\% com tempo de atuação entre 5 e 20 anos e $32,04 \%$ com mais de 20 anos.

\section{AS EMPRESAS}

A pesquisa revelou que $69,69 \%$ destas empresas contam com mais de 40 anos de atuação, caracterizadas como maduras. Possuem $51,52 \%$ e $84,52 \%$ de 1 unidade de almoxarifado e suprimento, respectivamente por unidade operacional. Por outro lado, $55,56 \%$ declararam que estas unidades administram mais de 5.000 itens em estoque e $71,43 \%$ que estes valores são superiores a $\mathrm{R} \$ 20$ milhões, o que caracteriza aspecto altamente negativo. Possui também uma grande concentração média de funcionários por unidade operacionais, sendo suprimentos o que mais concentra: 32,31 funcionários. Paradoxalmente, embora seu corpo funcional seja de alto nível cultural, estes carecem de informações especificas, pois apenas $42,72 \%$ responderam positivamente o conhecimento de todas as técnicas do STP., 19,42\% declararam terem recebidos treinamentos específicos.

\section{DIMENSÃO: ANÁLISE DE VALOR}

$\mathrm{Na}$ tabela 1 temos os resultados inerentes às perguntas 23 a 27 da dimensão analise de valor. O objeto da análise de valor é ver o grau de estrutura conceitual que o SEB, de forma global, tem em relação a este princípio, o que para Womack (1998) constitui-se num elemento fundamental do PE. 
Tabela 1 - Analise de valor

\begin{tabular}{c|c|c|c|c|c|c|c|c|c|c|c}
\multicolumn{10}{c}{ Dimensão: Análise de Valor } \\
\hline Perguntas & Média & Mediana & Desv Pad & CV & Q1 & Q3 & Min & Max & Moda & N & IC \\
\hline Av23 & 3,51 & 4 & 0,75 & $21 \%$ & 3 & 4 & 1 & 5 & 4 & 103 & 0,15 \\
\hline Av24 & 3,52 & 4 & 0,8 & $23 \%$ & 3 & 4 & 1 & 5 & 4 & 103 & 0,15 \\
\hline Av25 & 3,08 & 3 & 0,91 & $30 \%$ & 3 & 4 & 1 & 5 & 3 & 103 & 0,18 \\
\hline Av26 & 2,91 & 3 & 1,09 & $38 \%$ & 2 & 4 & 1 & 5 & 3 & 103 & 0,21 \\
\hline Av27 & 2,89 & 3 & 1,12 & $39 \%$ & 2 & 4 & 1 & 5 & 3 & 103 & 0,22 \\
\hline Geral & $\mathbf{3 , 1 8}$ & $\mathbf{3 , 2}$ & $\mathbf{0 , 7 5}$ & $\mathbf{2 4 \%}$ & $\mathbf{2 , 6}$ & $\mathbf{3 , 8}$ & $\mathbf{1}$ & $\mathbf{4 , 6}$ & $\mathbf{3}$ & $\mathbf{1 0 3}$ & $\mathbf{0 , 1 4}$ \\
\hline
\end{tabular}

Tabela elaborados pelos autores com dados da pesquisa

As questões 24 e 23, ou seja, "Tem conhecimento dos objetivos do cliente? e "Tem conhecimento das características do cliente?”, respectivamente, tiveram as melhores médias: 3,52 e 3,51. Por outro lado, a pergunta 27, "Tem conhecimento dos locais da tomada de serviços?" Teve a menor média com 2,89. No geral, esta dimensão teve média de 3,18, uma boa variabilidade de apenas $24 \%$, sendo limitada sua aceitação em $50 \%$.

Dado o fato do alto índice dos respondentes possuírem grau de escolaridade elevada e 50\% deles serem gerentes, ou seja, nível de conhecimento e responsabilidade maior, em tese, as médias gerais deveriam ser mais elevadas.

A tabela 2, resume, no aspecto da dimensão valor, a performance de cada controlador: Governo (representado pelas empresas estatais) e privado. Observe o baixo CV 23\%, mostrando uma boa variabilidade e o baixíssimo p-valor de 0,065 o qual indica a alta consistência nos números.

O setor privado teve média 10,61\% superior a do Governo: 3,44 (68,8\%) e 3,11 (62,2\%), respectivamente, o qual para Sellito et al (2003) caracteriza um número aceitável como evidência de capacidade para receber e implantar a filosofia PE na empresa, não esquecendo que trata-se apenas da análise de valor. Por outro lado, Souto (2000), citando Koskela (1997), chama atenção para um outro aspecto, tendo em vista o baixo índice das perguntas 25 a 27: os fluxos de conversões. Para ele, são dois tipos: fluxo de conversões e fluxo de atividades complementares. O primeiro são atividades de custos que agregam valor ao produto, o segundo, não. Dissertando sobre as atividades na construção civil, porém, generalizando, Koskela afirma que os fluxos de atividades complementares são pouco controlados e melhorados, os quais tornam-se fluxos instáveis, propícios a expansão de atividades que não adicionam valor. Considerando que as perguntas 25 a 27 atingem diretamente as atividades complementares, os baixos índices nestas três questões representam pontos de atenção importantes para o setor. Nesta mesma linha de ação, Silva Et Al (2015), em estudo sobre geração de valor no contexto de estratégia, testou três atributos de valor, em uma fábrica de Calçados, vindo a concluir que não há criação de valor sem a combinação de pelo menos dois atributos combinados. Esta afirmação leva a conclusão que para construir valor é preciso haver uma sinergia, ou seja, afinamento de ideias, propósitos e esforços em sentido único. 
Tabela 2 - Análise de valor x controlador

\begin{tabular}{l|c|c|c|c|c|c|c|c|c|c}
\hline Dimensão & Controlador & Média & Mediana & Desv Pad & CV & Min & Max & N & IC & P-valor \\
\hline \multirow{2}{*}{ Av - (23 a 27 } & Governo & 3,11 & 3,2 & 0,72 & $23 \%$ & 1 & 4,6 & 79 & 0,16 & \multirow{2}{*}{0,055} \\
\cline { 2 - 12 } & Privado & 3,44 & 3,7 & 0,79 & $23 \%$ & 2 & 4,4 & 24 & 0,32 & \\
\hline
\end{tabular}

Tabela elaborados pelos autores com dados da pesquisa

\section{DIMENSÃO: FLUXO CONTÍNUO}

Tabela 3 - Fluxo Contínuo

\begin{tabular}{c|c|c|c|c|c|c|c|c|c|c|c}
\hline \multicolumn{10}{c}{ Dimensão: Fluxo Continuo } \\
\hline Perguntas & Média & Mediana & Desv Pad & CV & Q1 & Q3 & Min & Max & Moda & N & IC \\
\hline Fc 28 & 3,34 & 4 & 0,97 & $29 \%$ & 3 & 4 & 1 & 5 & 4 & 103 & 0,19 \\
\hline Fc 29 & 3,37 & 4 & 0,93 & $28 \%$ & 3 & 4 & 1 & 5 & 4 & 103 & 0,18 \\
\hline Fc 30 & 3,24 & 3 & 0,99 & $31 \%$ & 3 & 4 & 1 & 5 & 4 & 103 & 0,19 \\
\hline Fc 31 & 3,1 & 3 & 1,05 & $34 \%$ & 2 & 4 & 1 & 5 & 4 & 103 & 0,2 \\
\hline Fc 32 & 2,94 & 3 & 0,88 & $30 \%$ & 2 & 4 & 1 & 5 & 3 & 103 & 0,17 \\
\hline Fc 33 & 3,5 & 4 & 0,98 & $28 \%$ & 3 & 4 & 1 & 5 & 4 & 103 & 0,19 \\
\hline Geral & $\mathbf{3 , 2 5}$ & $\mathbf{3 , 5}$ & $\mathbf{0 , 8 6}$ & $\mathbf{2 7 \%}$ & $\mathbf{2 , 8}$ & $\mathbf{3 , 8}$ & $\mathbf{1}$ & $\mathbf{5}$ & $\mathbf{3 , 8}$ & $\mathbf{1 0 3}$ & $\mathbf{0 , 1 7}$ \\
\hline
\end{tabular}

Tabela elaborada pelos autores com dados da pesquisa

A tabela 3 trata das questões 28 a 33. Este quadro, diferente da dimensão valor, tem uma média ligeiramente superior: 3,25 contra 3,18 do anterior. A pergunta 33 (é capaz de entender a importância da velocidade?) obteve melhor média com 3,5, um pouco acima da média geral, o que demonstra uma preocupação com o sentido de ação, de urgência, pois, segundo Antunes et al (2008), velocidade, associado a eficácia, são as palavras-chave do paradigma da produção em que vivemos no pós choque do petróleo. A pergunta 29 (é capaz de identificar suas perdas?) obteve a segunda melhor média com 3,37, o que mostra uma relativa preocupação que os profissionais das empresas têm com perdas e desperdícios, o que para Ohno (1997), é o princípio fundamental da filosofia STP/PE. Para ele, combater os desperdícios deve ser a principal preocupação de cada um.

A Pergunta 28 (tem conhecimento do conceito de perdas?) ficou em terceiro com média de 3,24. Este número, mesmo sendo muito próximo da média da pergunta 28 , revela um paradoxo conceitual, pois consegue-se identificar ou tipificar as perdas com uma sensibilidade inferior ao conhecimento dos conceitos, o que para Robbins (2002) caracteriza atos por intuição. A pergunta 32 (é capaz de eliminar suas perdas?) Ficou com a menor média: 2,94.

Esta média reforça o comentário sobre o paradoxo, tendo em vista que o conjunto é capaz de identificar as perdas e tem conhecimento dos conceitos, mas são incapazes de eliminar as perdas. Ghinato (1995) defende que o STP/PE está estruturado sobre a bases da completa eliminação de perdas. Pergher Et al (2011) implementou estudo das 7 perdas do STP na perspectiva do TOC e encontrou uma 8 perda, a "Pergas", ou seja, é um desperdício que se fundamenta nos índices globais de produtividades, levando o autor a sugerir um novo conceito na teoria das perdas do STP. Neste sentido, considerando que as empresas do SEB são grandes grupos empresariais, de atuação internacional, a observância da Pergas neste contexto, revestese de importância fundamental. 
Tabela 4 - Fluxo Contínuo x Controladores

\begin{tabular}{c|c|c|c|c|c|c|c|c|c|c}
\hline Dimensão & Controlador & Média & Mediana & Desv Pad & CV & Min & Max & N & IC & P-valor \\
\hline \multirow{2}{*}{ Fc (28 a 33) } & Governo & 3,17 & 3,3 & 0,87 & $27 \%$ & 1 & 5 & 79 & 0,19 & \multirow{2}{*}{0,111} \\
\cline { 2 - 12 } & Privado & 3,49 & 3,7 & 0,8 & $23 \%$ & 1 & 4,7 & 24 & 0,32 & \\
\hline
\end{tabular}

Tabela elaborados pelos autores com dados da pesquisa

Através da tabela 4 foi analisado o Fluxo Contínuo sob a perspectiva dos controladores: Governo x Privado (Iniciativa privada).

Observamos que a performance é superior da iniciativa privada frente as empresas do governo: 3,49 e 3,17, respectivamente. Além da boa média, o privado também teve melhor CV, com 23\% contra 27\% do Governo, o que em ambos os casos são índices bons. O p-valor, baixo 0,111 indica uma consistência forte nos dados analisados. Os intervalos de confiança, IC, foram calculados a 95\%.

\section{DIMENSÃO: FLUXO BALANCEADO}

Para Monden (2015), fluxo balanceado objetiva a alta produtividade através do trabalho intensivo de um balanceamento em linha entre todos os processos em termos de ritmo e produção. Na tabela abaixo, estão dispostos os resultados da pesquisa referente as perguntas 34 a 39. O Fluxo balanceado é um conceito que na visão de Womack e Jones (1996) tem a ver com processos internos e externos, importância dada a estes processos além da multifuncionalidade, um dos fundamentos do PE/STP.

Tabela 5 - Fluxo balanceado

\begin{tabular}{c|c|c|c|c|c|c|c|c|c|c|c}
\hline \multicolumn{10}{c}{ Dimensão: Fluxo Balanceado } \\
\hline Perguntas & Média & Mediana & Desv Pad & CV & Q1 & Q3 & Min & Max & Moda & N & IC \\
\hline Fb 34 & 3,91 & 4 & 0,94 & $24 \%$ & 4 & 5 & 1 & 5 & 4 & 103 & 0,18 \\
\hline Fb 35 & 3,94 & 4 & 0,83 & $21 \%$ & 4 & 4 & 1 & 5 & 4 & 103 & 0,16 \\
\hline Fb 36 & 3,82 & 4 & 0,93 & $24 \%$ & 4 & 4 & 1 & 5 & 4 & 103 & 0,18 \\
\hline Fb 37 & 3,19 & 3 & 0,97 & $30 \%$ & 3 & 4 & 1 & 5 & 3 & 103 & 0,19 \\
\hline Fb 38 & 3,53 & 4 & 0,93 & $26 \%$ & 3 & 4 & 1 & 5 & 4 & 103 & 0,18 \\
\hline Fb 39 & 3,54 & 4 & 0,92 & $26 \%$ & 3 & 4 & 1 & 5 & 4 & 103 & 0,18 \\
\hline Geral & $\mathbf{3 , 6 6}$ & $\mathbf{3 , 8}$ & $\mathbf{0 , 6 8}$ & $\mathbf{1 9 \%}$ & $\mathbf{3 , 4}$ & $\mathbf{4}$ & $\mathbf{1}$ & $\mathbf{4 , 8}$ & $\mathbf{4}$ & $\mathbf{1 0 3}$ & $\mathbf{0 , 1 3}$ \\
\hline
\end{tabular}

Tabela elaborados pelos autores com dados da pesquisa.

A dimensão Fluxo balanceado teve a melhor média das cinco dimensões com 3,66 com destaques para as perguntas 35 e 34, "qual a importância dada ao mapeamento de seus processos? "e "tem conhecimento de seus processos?" os quais tiveram médias de 3,94 e 3,91, respectivamente. Também nesta dimensão, a questão do paradoxo manifestou-se, tendo a importância do processo nota superior ao conhecimento do processo. Por outro lado, esta dimensão apresenta um quadro equilibrado entre as médias das perguntas, no qual variou de 3,19 a 3,94, com CV de apenas 19\% no quadro geral. A pergunta 37 (Qual a importância dada à medição de processos de parceiros?) teve a menor média com 3,19, sendo este número indicador da pouca importância com que as empesas do SEB dão a seus parceiros, que formam a cadeia de valor

A pesquisa aponta que num contexto global, os resultados mostraram uma preocupação 
dos profissionais com fluxos, processos e o consequente desenvolvimento destes nos cinco segmentos do SEB. No âmbito da dimensão Fluxo balanceado, cruzando controladores, a exemplo dos quadros anteriores, o setor privado teve melhor média frente as empresas do governo: 3,97 contra 3,56 com um baixo CV: 11 e 20\% e p-valor 0,009. Os números mostram o bom desempenho no grau de preparação das empresas privadas para recebimento da PE.

Pacheco Et al (2014) consideram o balanceamento do fluxo algo de importância singular e empreenderam pesquisa visando determinar a importância do fluxo ou da capacidade instalada. Tal estudo concluiu que o balanceamento do fluxo é superior em termos da otimização do desempenho da manufatura em relação aos aspectos da qualidade, variabilidade e velocidade. Por outro lado, considerando os avanços de outras modalidades de geração de energia, sobretudo a energia solar, em um futuro próximo a engenharia das plantas de geração hidroelétrica estarão com a questão do balanceamento da capacidade instalada na ordem do dia, tanto para as estatais quanto para o setor privado. Marques da Silva (2015), em seu Relatório ao Senado brasileiro, chama atenção ao potencial do Brasil para desenvolvimento da energia solar e descreve uma série de providências institucionais que devem ser incrementadas. Neste sentido, Carvalho e Calvete (2010) nos lembram dos avanços tecnológicos que permitem tornar esta fonte de energia acessível a maioria da população, enfatizando de forma positiva as questões ambientais.

Tabela 6 - Fluxo Balanceado x controladores

\begin{tabular}{c|c|c|c|c|c|c|c|c|c|c}
\hline Dimensão & Controlador & Média & Mediana & Desv Pad & CV & Min & Max & N & IC & P-valor \\
\hline \multirow{2}{*}{$\mathrm{Fb}$ (34 a 39) } & Governo & 3,56 & 3,8 & 0,72 & $20 \%$ & 1 & 4,7 & 79 & 0,16 & \multirow{2}{*}{0,009} \\
\cline { 2 - 12 } & Privado & 3,97 & 4 & 0,44 & $11 \%$ & 2,8 & 4,8 & 24 & 0,18 & \\
\hline
\end{tabular}

Tabela elaborados pelos autores com dados da pesquisa

\section{DIMENSÃO: PRODUÇÃO PUXADA}

A dimensão Produção Puxada teve a segunda melhor média entre as dimensões com 3,65. As médias entre as perguntas variaram de 3,5 a 3,77, o que demonstra quase um empate técnico, o que levou a um CV médio de $22 \%$.

As perguntas 40, 41 e 42 (qual a consideração dada a voz do cliente? qual a capacidade de ouvir a voz do cliente? e qual a importância dada a voz do cliente?) com 3,77, 3,7 e 3,7 respectivamente. Os dados mostram a preocupação das empresas com a satisfação do cliente.

Tabela 7 - Produção puxada

\begin{tabular}{c|c|c|c|c|c|c|c|c|c|c|c}
\hline \multicolumn{10}{c}{ Dimensão: Produção Puxada } \\
\hline Perguntas & Média & Mediana & Desv Pad & CV & Q1 & Q3 & Min & Max & Moda & N & IC \\
\hline Pp 40 & 3,7 & 4 & 0,88 & $24 \%$ & 3 & 4 & 1 & 5 & 4 & 103 & 0,17 \\
\hline Pp 41 & 3,77 & 4 & 0,91 & $24 \%$ & 3 & 4 & 1 & 5 & 4 & 103 & 0,18 \\
\hline Pp 42 & 3,7 & 4 & 0,88 & $24 \%$ & 3 & 4 & 1 & 5 & 4 & 103 & 0,17 \\
\hline Pp 43 & 3,5 & 4 & 0,91 & $26 \%$ & 3 & 4 & 1 & 5 & 4 & 103 & 0,17 \\
\hline Pp 44 & 3,68 & 4 & 0,89 & $24 \%$ & 3 & 4 & 1 & 5 & 4 & 103 & 0,17 \\
\hline Pp 45 & 3,53 & 4 & 1 & $28 \%$ & 3 & 4 & 1 & 5 & 4 & 103 & 0,19 \\
\hline Geral & $\mathbf{3 , 6 5}$ & $\mathbf{3 , 8}$ & $\mathbf{0 , 8}$ & $\mathbf{2 2 \%}$ & $\mathbf{3 , 3}$ & $\mathbf{4}$ & $\mathbf{1}$ & $\mathbf{5}$ & $\mathbf{4}$ & $\mathbf{1 0 3}$ & $\mathbf{0 , 1 6}$ \\
\hline
\end{tabular}

Tabela elaborados pelos autores com dados da pesquisa 
A pergunta 45 (qual a intensidade da interação com o cliente?) teve a menor média com 3,53. O quadro revela números nos quais se dá atenção e importância ao cliente, porém uma relação sem intensidade.

Analisando o quadro de forma genérica, observamos que há um entendimento da produção puxada, sobretudo nas empresas privadas. Entretanto, os números revelam um paradoxo nesta dimensão. O JIT é um dos pilares do STP/PE e quando observamos os números da caracterização das empresas, vimos estoques elevados nas unidades operacionais, o que vai de encontro a boa pratica do JIT, ou seja, o planejamento está sendo negligenciado, na melhor das hipóteses. Ohno (1997) observa que o JIT exerce papel fundamental, significando a produção no tempo e quantidade certa. Para ele, o JIT integralmente implantado levará a empresa ao estoque zero, eliminando-se assim uma atividade que não agrega valor (estoque).

Na mesma linha de pensamento, Votto e Fernandes (2013), em estudo onde propôs o PE a empresas de bens de capital, lembrou Liker (2005) que é taxativo em sua afirmação segundo o qual a principal finalidade da produção puxada é evitar a superprodução, controlando o estoque e uma série de desperdícios advindos da não observância do princípio. Porém, nem tudo é fácil nem muito prático, servindo de consolo aos resultados desta dimensão. Estudos levados a efeito por Saurin Et al (2010) com 49 empresas líderes no Brasil e exterior e todas com PE implantado em diferentes níveis, concluiu que a principal dificuldade dos gestores e operadores reside exatamente na produção puxada, apesar da educação formal nas universidades e capacitação promovida pelas empresas. Desta forma, o estudo concluiu com orientação de mais capacitação ao corpo funcional.

Tabela 8 - Produção puxada x controlador

\begin{tabular}{c|c|c|c|c|c|c|c|c|c|c}
\hline Dimensão & Controlador & Média & Mediana & Desv Pad & CV & Min & Max & N & IC & P-valor \\
\hline \multirow{2}{*}{ Pp(40 a 45) } & Governo & 3,52 & 3,5 & 0,85 & $24 \%$ & 1 & 5 & 79 & 0,19 & \multirow{2}{*}{0,004} \\
\cline { 2 - 12 } & Privado & 4,05 & 4 & 0,44 & $11 \%$ & 3 & 5 & 24 & 0,18 & \\
\hline
\end{tabular}

Tabela elaborados pelos autores com dados da pesquisa

No que se refere aos controladores, o setor privado tem média de 4,05 contra 3,52 das empresas estatais. O CV do setor privado também é menor: 11 contra 24\% mostrando uma baixa variabilidade entre seus atores internos, números estes consistentes como demonstra o baixo p-valor de 0,004. O destaque do setor privado é um fato que se repete em todas as dimensões. Desta forma, observamos a diferença entre empresas estatais e privada, no aspecto da atenção ao cliente.

\section{DIMENSÃO: MELHORIA CONTÍNUA}

O 14 Princípio de LIKER e MEIER (2007) diz textualmente: “Tornar-se uma organização de aprendizagem pela reflexão incansável e pela melhoria contínua". A Melhoria contínua é fruto de repaginação de várias técnicas do PE/STP, tais como: "análises dos 5 porquês", "planejar, fazer, verificar, agir”, que possibilita o profissional ou o grupo de funcionários a determinar a raiz da ineficiência pontual e, através desta identificação, determinar as contramedidas necessárias contra o erro. Melhoria contínua, para Pinto (2009), é sinônimo de ação, pois requer uma disciplina de proatividade e vontade de fazer, pois a melhoria ocorre pela intercessão de três elementos: "Conhecimento, desejo e saber fazer", o processo pelo qual as empresas sobrevivem e se perpetuam no tempo e no espaço. 
Na tabela 47 apresenta-se as médias da pesquisa da dimensão Melhoria Contínua, referente às perguntas 45 a 51. Este bloco teve média de 3,53 e um CV de 23\%, destacando-se as perguntas 46, 50 e 47 (Conhece o conceito de melhoria contínua? Qual a importância dada a melhoria contínua? e tem capacidade de promover a melhoria contínua?) com médias 3,69, 3,67 e 3,58 respectivamente. A menor média ficou por conta da pergunta 51 (qual a intensidade da melhoria contínua?) com 3,29 e a maior variação do grupo com CV 28.

A dimensão Melhoria Contínua está intimamente ligada ao conceito da "Inovação", tão em moda atualmente. Mesquita e Alliprandini (2003), em estudos nas indústrias de autopeças, no Brasil, visando a identificação de competências para a melhoria contínua, entre outros aspectos, concluíram que muitas empresas caem na chamada "armadilha do sucesso", ao imaginarem que por possuírem a certificação ISO 9000, praticam a melhoria contínua.

Para estes pesquisadores, não seria exagero afirmar que as empresas, apesar de seu grau de maturidade, são carentes de profissionais voltados a inovação/melhoria dentro de uma visão sistêmica. Indo além, eles destacam que identificar as competências é fundamental, pois, desta forma, produz uma melhoria contínua capaz de preparar a empresa ao futuro incerto.

Nesta linha de ação, Oprime Et al (2010), ao analisarem 42 projetos de melhoria contínua concluíram que os melhores e com maior probabilidade de atingir os objetivos estratégicos eram os com foco na agilidade e flexibilidade. Nesta mesma perspectiva, Gonzalez e Martins (2011), ao estudarem empresas do setor automobilístico, enfatizam a concorrência de um mundo cada vez mais globalizado, exigindo que as empresas invistam cada vez mais na inovação com ciclo reduzido para fazer frente as mudanças tecnológicas, econômicas e institucionais que a sociedade atravessa.

Tabela 9 - Melhoria contínua

\section{Dimensão: Melhoria Continua}

\begin{tabular}{c|c|c|c|c|c|c|c|c|c|c|c}
\hline Perguntas & Média & Mediana & Desv Pad & CV & Q1 & Q3 & Min & Max & Moda & N & IC \\
\hline Mc 46 & 3,69 & 4 & 0,91 & $25 \%$ & 3 & 4 & 1 & 5 & 4 & 103 & 0,18 \\
\hline Mc 47 & 3,58 & 4 & 0,87 & $24 \%$ & 3 & 4 & 1 & 5 & 4 & 103 & 0,17 \\
\hline Mc 48 & 3,57 & 4 & 0,89 & $25 \%$ & 3 & 4 & 1 & 5 & 4 & 103 & 0,17 \\
\hline Mc 49 & 3,4 & 4 & 0,91 & $27 \%$ & 3 & 4 & 1 & 5 & 4 & 103 & 0,18 \\
\hline Mc 50 & 3,67 & 4 & 0,9 & $25 \%$ & 3 & 4 & 1 & 5 & 4 & 103 & 0,17 \\
\hline Mc 51 & 3,29 & 3 & 0,91 & $28 \%$ & 3 & 4 & 1 & 5 & 4 & 103 & 0,18 \\
\hline Geral & $\mathbf{3 , 5 3}$ & $\mathbf{3 , 8}$ & $\mathbf{0 , 7 7}$ & $\mathbf{2 2 \%}$ & $\mathbf{3 , 2}$ & $\mathbf{4}$ & $\mathbf{1}$ & $\mathbf{5}$ & $\mathbf{4}$ & $\mathbf{1 0 3}$ & $\mathbf{0 , 1 5}$ \\
\hline
\end{tabular}

Tabela elaborados pelos autores com dados da pesquisa

A tabela 10 mostra o que todas as outras dimensões revelaram: hegemonia do setor privado, que, neste quadro, teve média de 3,92 contra 3,42 do Governo, através das empresas estatais. Estes números mostram que o setor privado está mais atento aos processos de inovação através da melhoria contínua. 
Tabela 10 - Melhoria contínua x Controlador

\begin{tabular}{c|c|c|c|c|c|c|c|c|c|c}
\hline Dimensão & Controlador & Média & Mediana & Desv Pad & CV & Min & Max & N & IC & P-valor \\
\hline \multirow{2}{*}{ Mc (46 a 51) } & Governo & 3,42 & 3,7 & 0,77 & $23 \%$ & 1 & 4,7 & 79 & 0,17 & \multirow{2}{*}{0,004} \\
\cline { 2 - 10 } & Privado & 3,92 & 4 & 0,63 & $16 \%$ & 2,7 & 5 & 24 & 0,25 & \\
\hline
\end{tabular}

Tabela elaborados pelos autores com dados da pesquisa

\section{RESUMO DAS 5 DIMENSÕES}

Observa-se que a variabilidade é baixa tanto nas questões quanto nas dimensões, em virtude do baixo CV $(<50 \%)$, o que demonstra a homogeneidade dos dados. Nas questões, a melhor média ficou com a $3^{\mathrm{a}}$ Dimensão: fluxo balanceado com 3,66, seguida da $4^{\mathrm{a}}$ Dimensão: produção puxada, ficando a $1^{\mathrm{a}}$ Dimensão: Valor, com a pior pontuação: 3,18 .

A dimensão Valor como a pior pontuação é um dado preocupante, pois é a que de fato cria valor.

Gráfico 2 - Média das dimensões

COMPARA AS DIMENSÕES NO QUADRO GERAL

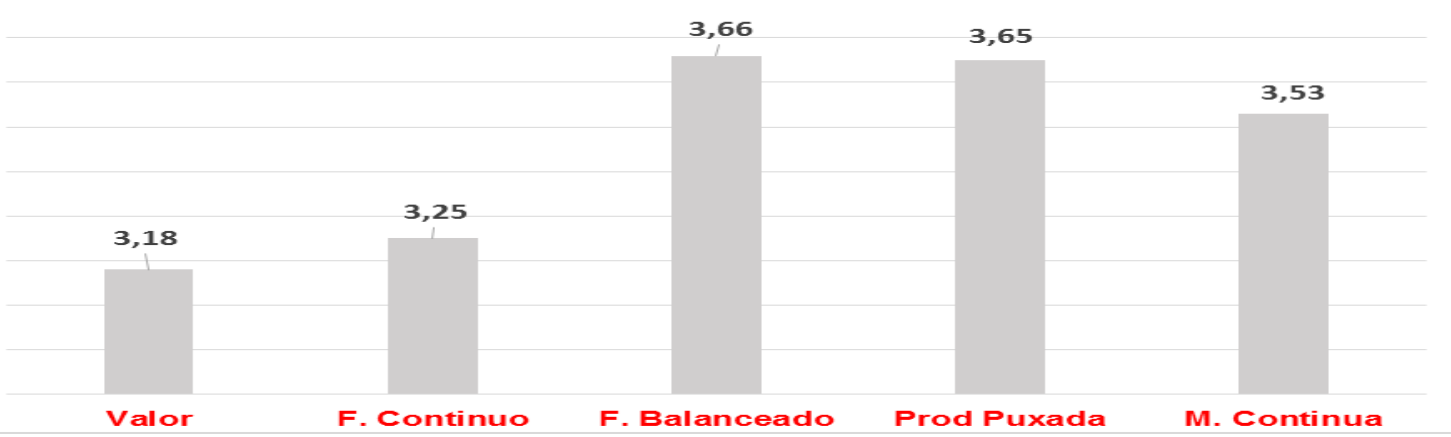

Gráfico elaborado pelos autores com dados da pesquisa

A seguir resumiremos as cinco dimensões para os segmentos e controladores, mostrando os destaques em termos de eficiência de cada segmento e controlador.

Na tabela 11 abaixo, resume a eficiência do setor privado, com média de 3,79 frente as empresas estatais, com 3,36.

Tabela 11 - Compara controlador para média geral das 5 dimensões

\begin{tabular}{c|c|c|c|c|c|c|c|c|c|c}
\hline Dimensão & Controlador & Média & Mediana & DP & CV & Min & Max & N & IC & P-valor \\
\hline \multirow{2}{*}{ Geral } & Governo & 3,36 & 3,5 & 0,62 & $18 \%$ & 1 & 4,4 & 79 & 0,14 & \multirow{2}{*}{0,003} \\
\cline { 2 - 12 } & Privado & 3,79 & 3,9 & 0,45 & $12 \%$ & 2,6 & 4,6 & 24 & 0,18 & \\
\hline
\end{tabular}

Tabela elaborados pelos autores com dados da pesquisa

\section{PESQUISAS CCEE / RESULTADOS PATRIMONIAIS}

Diante dos números da pesquisa de campo, no qual avaliamos os números dos respondentes, efetuamos a pesquisa bibliográfica no âmbito da Comissão de Comercialização de Energia Elétrica - CCEE., órgão ligado a ANEEL onde analisamos todos os leilões de energia elétrica entre os anos de 2004 à 2014, nos aspectos da Energia nova, Energia existente e PLD. 
Avaliamos também os balanços patrimoniais e os Demonstrativos dos Resultados dos Exercícios - DRE dos anos 2013 e 2014. O objetivo desta pesquisa foi testar a consistência da pesquisa de campo.

\section{1 - Leilões da CCEE}

Na tabela abaixo analisamos os 24 leilões de energia, realizados através da CCEE, no período de 2004 a 2014, abrangendo a energia existente, energia nova e mercado de curto prazo (PLD). No período, a energia existente negociou volume de energia de mais de 1,924 TWh, em sete leilões, com até oito anos de contratos. A energia nova, negociou 1,810 TWh de energia, em onze leilões, com contratos de 30 anos, enquanto o PLD negociou 189,22 GWh, ou seja, pouco mais de 10\% da energia nova, em 6 leilões de ajustes, ocorridos entre 2006 e 2012.

Energia existente, para Tolmasquim (2010), é um termo aplicado no âmbito da CCEE, para leilões de oferta de energia de médio prazo, onde somente participam usinas já em funcionamento, com grande peso de empreendimentos já amortizados, sobretudo organizações estatais, onde, ao final do pregão, já poderá firmar contrato de entrega para o mesmo ano. Energia nova, por sua vez, segundo o mesmo pesquisador, na prática, são leilões que ocorrem para ofertar energia futura, de longo prazo.

O PLD, para Vela e Oliveira (2010), está dentro de um mercado de curtíssimo prazo e as liquidações dar-se-ão com preços sob forte influência do custo marginal de operações - CMO e difere das duas outras modalidades, segundo Tolmasquim (2010), por possuir um teto e a inexistência de restrição, quanto a transmissão do produto. Neste sentido, o PLD sofreu oscilações no período dos leilões.

Tabela 12 - Leilões de energia da CCEE 2004 a 2014

\begin{tabular}{c|r|r|r|r|r|r|r|r|r}
\hline \multirow{2}{*}{ ANO } & \multicolumn{3}{|c|}{ ENERGIA EXISTENTE } & \multicolumn{3}{c|}{ ENERGIA NOVA } & \multicolumn{3}{c}{ PLD } \\
\cline { 2 - 10 } & OFERTA MW/h & $\begin{array}{c}\text { PÇ } \\
\text { (RȘ)/MW/h/h }\end{array}$ & $\begin{array}{c}\text { Variação } \\
(\%)\end{array}$ & OFERTAMW/h/h & $\begin{array}{c}\text { PÇ } \\
\text { (R\$̧)/MW/h }\end{array}$ & $\begin{array}{c}\text { Variação } \\
(\%)\end{array}$ & OFERTA MW/h & PÇ (RŞ)/MW/h & $\begin{array}{c}\text { Variação } \\
(\%)\end{array}$ \\
\hline 2004 & & & & & & & & & \\
\hline 2005 & 1.814 .506 .967 & 70,19 & & 264.547 .512 & 114,78 & & & & \\
\hline 2006 & 14.306 .112 & 105,00 & $49,59 \%$ & 419.973 .552 & 124,66 & $8,61 \%$ & 60.720 & 53,81 & \\
\hline 2007 & & & & 188.039 .280 & 129,14 & $12,51 \%$ & 1.869 .929 & 119,28 & $121,67 \%$ \\
\hline 2008 & & & & 31.819 .128 & 98,98 & $-13,77 \%$ & 867.392 & 154,82 & $187,72 \%$ \\
\hline 2009 & 3.637 .392 & 99,00 & $41,05 \%$ & 262.992 & 144,00 & $25,46 \%$ & 8.668 .422 & 145,67 & $170,71 \%$ \\
\hline 2010 & 2.551 .488 & 103,00 & $46,74 \%$ & 340.574 .640 & 75,43 & $-34,28 \%$ & & & \\
\hline 2011 & 5.129 .280 & 79,99 & $13,96 \%$ & 285.509 .858 & 102,07 & $-11,07 \%$ & 177.205 .511 & 109,65 & $103,78 \%$ \\
\hline 2012 & & & & 39.602 .981 & 93,46 & $-18,57 \%$ & 551.557 & 128,50 & $138,79 \%$ \\
\hline 2013 & 11.318 .160 & 166,60 & $137,36 \%$ & 199.685 .688 & 111,81 & $-2,58 \%$ & & & \\
\hline 2014 & 73.113 .113 & 270,81 & $285,82 \%$ & 40.313 .563 & 127,32 & $10,93 \%$ & & & \\
\hline Medias & 274.937 .502 & 127,80 & $95,75 \%$ & 181.032 .919 & 112,17 & $-2,53 \%$ & 31.537 .255 & 118,62 & $144,54 \%$ \\
\hline
\end{tabular}

Tabela elaborados pelos autores com dados da pesquisa

Embora os preços médios das três modalidades sejam próximos, ou seja, $\mathrm{R} \$ 127,80, \mathrm{R} \$$ 112,17 e R\$118,62, por MWh da energia existente, energia nova e PLD, respectivamente, os leilões da energia existente tiveram variação elevada, 95,75\% contra uma inflação de 71,39. A 
energia nova, com preço 12,23\% menor, R \$112,17 teve variação negativa de 2,53\% frente o mesmo cenário inflacionário. A PLD por sua vez, teve a maior variação: 144,54\% para uma inflação de 45,16\%.

\section{2 - Demonstrações financeiras}

Foram analisadas todas as empresas participantes da pesquisa com objetivo de verificar o desempenho financeiro dos exercícios fiscais de 2013 e 2014, de forma objetiva e sem se ater a detalhes, verificamos se a empresa teve lucro ou prejuízo no período. A tabela abaixo mostra a performance dos segmentos a partir do desempenho de suas empresas, onde Transmissão apresentou DRE negativo com 35,71\%; Distribuição, segundo melhor colocado com 46,15\% e Geração com 53,85\%.

No que se refere aos controladores, as empresas estatais, representantes do governo, tiveram pior desempenho geral de 50,00\%. O setor privado teve 33,33\% de participação nos prejuízos. No geral o SEB teve 45,45\% de prejuízo, ou seja, do total de 33 empresas, 15 apresentaram DRE negativo nos dois anos fiscal.

Tabela 13 - Compara controladores para eficiência de gestão

\begin{tabular}{|c|c|c|c|c|c|c|c|c|c|c|c|c|}
\hline \multicolumn{12}{|c|}{ Empresas Participantes que Apresentaram DRE Negativo x Controlador } & \multirow{5}{*}{$\begin{array}{c}\text { Média gera } \\
\text { com as } 5 \\
\text { Dimensões }\end{array}$} \\
\hline \multirow{12}{*}{ 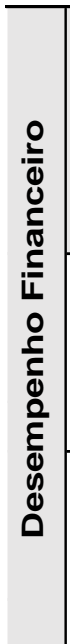 } & \multirow{4}{*}{$\begin{array}{l}\frac{1}{0} \\
\frac{0}{0} \\
\frac{\pi}{0} \\
\frac{0}{2} \\
\frac{1}{0} \\
0\end{array}$} & \multirow{4}{*}{ Segmento } & \multicolumn{9}{|c|}{ Exercicios } & \\
\hline & & & \multicolumn{3}{|c|}{2013} & \multicolumn{3}{|c|}{2014} & \multicolumn{3}{|c|}{ Médias } & \\
\hline & & & \multicolumn{2}{|c|}{ Frequência } & \multirow[b]{2}{*}{$\%$} & \multicolumn{2}{|c|}{ Frequência } & \multirow[b]{2}{*}{$\%$} & \multicolumn{2}{|c|}{ Frequência } & \multirow[b]{2}{*}{$\%$} & \\
\hline & & & Total & $\begin{array}{c}\text { C/ DRE } \\
\text { Negativo }\end{array}$ & & Total & $\begin{array}{c}\text { C/ DRE } \\
\text { Negativo }\end{array}$ & & Total & $\begin{array}{c}\text { C/ DRE } \\
\text { Negativo }\end{array}$ & & \\
\hline & \multirow{4}{*}{ 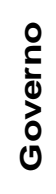 } & Transmissão & 7 & 2 & $28,57 \%$ & 7 & 2 & $28,57 \%$ & 7 & 2,00 & $28,57 \%$ & \multirow{4}{*}{3,42} \\
\hline & & Distribuição & 8 & 5 & $62,50 \%$ & 8 & 6 & $75,00 \%$ & 8 & 5,50 & $68,75 \%$ & \\
\hline & & Geração & 9 & 4 & $44,44 \%$ & 9 & 5 & $55,56 \%$ & 9 & 4,50 & $50,00 \%$ & \\
\hline & & Média & 8,0 & 3,7 & $45,83 \%$ & 8,0 & 4,3 & $54,17 \%$ & 8,0 & 4,0 & $50,00 \%$ & \\
\hline & \multirow{4}{*}{ 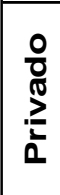 } & Transmissão & & & & & & & & & & \multirow{4}{*}{3,92} \\
\hline & & Distribuição & 5 & 1 & $20,00 \%$ & 5 & 2 & $40,00 \%$ & 5 & 1,50 & $30,00 \%$ & \\
\hline & & Geração & 4 & 2 & $50,00 \%$ & 4 & 1 & $25,00 \%$ & 4 & 1,50 & $37,50 \%$ & \\
\hline & & Média & 4,5 & 1,5 & $33,33 \%$ & 4,5 & 1,5 & $33,33 \%$ & 4,5 & 1,5 & $33,33 \%$ & \\
\hline
\end{tabular}

Tabela elaborados pelos autores com dados da pesquisa

\section{CONSIDERAÇÕES FINAIS}

Considerando que de forma geral o SEB possui uma razoável estrutura conceitual capaz de absorver a filosofia do PE/STP., em particular, no âmbito do controle acionário, o setor privado, apresentou melhor estrutura física e conceitual frente ao setor governamental.

Considerando também quanto as 5 dimensões, a variabilidade ficou em torno de $21 \%$ do CV e contrariando a lógica, a criação de valor teve a pior média, 3,18, contra a melhor, do fluxo balanceado com 3,66. Este ponto demonstrou um contrassenso com o atual paradigma, baseado na criação de valor. Quanto aos controladores, o governo teve média de 3,36 contra 3,79 no Privado ( $p$-valor $=0,003$ ). A média geral do SEB foi 3,65, o que corresponde a 65,45\%, número este que se situa no limite mínimo da escala de aceitação dos pesquisadores, que foi $66 \%$. 
E considerando os balanços patrimoniais e demonstrações financeiras, revelaram 50\% de resultados negativos nos períodos para o Governo e 33,33\% para as empresas privadas, demonstrando uma fragilidade nas gestões estatais. Os leiloes da CCEE mostraram a alta variação da energia existente, de 95,75\%, com substancial peso estatal, contra 2,53\% negativos da energia nova para um cenário inflacionário de $71,39 \%$.

Concluímos que as empresas do setor privado estão melhor posicionadas para enfrentar as dificuldades futuras na garantia do fornecimento e sobrevivência. Neste sentido, sugerimos a adoção da filosofia a todas empresas do setor elétrico brasileiro.

\section{REFERÊNCIAS}

ANTUNES, Junico; ALVAREZ, Roberto; BORTOLOTTO, Pedro; KLIPPEL, Marcelo;tonin PELLEGRIN, Ivan. Sistemas de produção - Conceitos e Práticas para Projeto e Gestão da Produção Enxuta. Porto Alegre: Bookman, 2008.

ARANTES, Nelio. Sistema de gestão empresarial - Conceitos permanentes na Administração de Empresas Validas. São Paulo: Atlas, 1994.

ARAÚJO, N. R. S.;LABURÚ, C. E. Uma análise da validação e confiabilidade da escala de opiniões da seleção de experimentos de química (EOSEQ). Ensaio-Pesquisa, Educação e Ciência, 11(2), 1-22. 2009

AUDITEC - Gestão Contábil. Disponível em: http://audtecgestao.com.br/capa.asp?infoid=1336 Acesso em 31 Mar. 2019.

BUTTNER, Anselmo. Toyotismo: Reduzindo o desperdício e aumentando a lucratividade. São Paulo: Pleiáde, 2008.

BYRNE, Art. Lean Turnaround: A grande virada. São Paulo: lean Institute Brasil, 2014.

CARVALHO, E. F. A.; CALVETE, M. J. F. ENERGIA SOLAR: Um passado, um presente, um futuro auspicioso. Revista Virtual de Química. Aveiro, Portugal. 2010.

CHUAHY, Eduardo e VICTER, Wagner Granja. A Construção e a desconstrução do setor elétrico brasileiro. Rio de Janeiro: Relume Dumará, 2002.

CORDEIRO, J. V. B. M.; RIBEIRO, R. V. Gestão de empresas. Curitiba: Associação Franciscana de Ensino Senhor Bom Jesus, 2002. (Coleção Gestão Empresarial).

CRONBACH, L.J. Coefficient Alpha and the internal structure of tests. Psychoketrika, 1951.

D`ARAUJO, R. P. O Setor elétrico brasileiro: Uma aventura mercantil. Brasília: CONFEA, 2009.

DOANE, David P.;SEWARD, Lori E. - Estatística aplicada a administração e a economia. Porto Alegre: Bookman, 2014

FACHINI, Fabio. Crise no setor elétrico brasileiroapós a medida provisória. $\mathbf{N}^{0} 579$ Monografia curso ciências econômicas, UFSC: 2015

GLOBA-RATES - <https://pt.global-rates.com/estatisticas-economicas/inflacao/indicede-precos-ao-consumidor/ipc/brasil.aspx> Acesso em: 31 Mar. 2019.

GHINATO, P. - Sistema Toyota de produção: mais do que simplesmente Just in Time. Produção, Revista Produção, v.3, n.2, 1995.

GONZALEZ, R. V. Dominguez; MARTINS, D. M. Fernando. Melhoria contínua e aprendizagem organizacional: múltiplos casos em empresas do setor automobilístico. Revista Gestão e Produção, vol 18, São Carlos, 2011. 
GUINLE, Eduardo. A Light e seus negócios da China. Rio de Janeiro, Jornal do Comércio, 1933.

INSTITUTO ACENDE BRASIL. Financiamento do setor elétrico. Ed. $\mathrm{n}^{\circ} 20$ / Fevereiro de 2018.

KING, G. How not to lie with statistics [Online] Disponível em: <http://gking.harvard.edu/files/mist.pdf $>$ Acesso em: 22 Jan. 2016.

KUIPER'S B. Critical decisions under uncertainty: representation and structure. Cog Sci 1988.

LEVY, David L.;SLOAN, Chain. Lean Production in International Supply. Management Review. 1997.

LIKER, J, K. O Modelo Toyota: 14 princípios de gestão do maior fabricante do mundo. Porto Alegre: Bookman, 2005.

LIKER, Jeffrey K. e MEIER, David. O Modelo Toyota - Manual de Aplicação. Porto Alegre: Bookman, 2007

LLAURADÓ, Oriol - Escala de Likert: o que é e como utiliza-la. Artigo da NETQUEST, 2010

MARQUES DA SILVA, Rutelly. Energia solar no Brasil: dos incentivos aos desafios Revista do Senado, 166, Brasília, 2015.

MESQUITA, Melissa; ALLIPRANDINI, D. Henrique. Competências Essenciais para a melhoria continua da produção: Estudo de caso em empresas da indústria de auto peças. Revista Gestão e Produção, Vol 10, São Carlos, 2003.

MONDEN, Y. Sistema Toyota de Produção: uma abordagem integrada ao just-intime. (4a ed.). Porto Alegre: Bookman, 2015.

MONTEIRO, E. Muller; SANTOS, E. Moutinho dos. Uso politico do setor elétrico brasileiro - Uma Metodologia de Análise Baseada na Teoria de Grupos de Pressão. São Paulo: SYNERGIA EDITORA, 2010.

MONTEIRO et. al. Confiabilidade em Questionários para Qualidade: Um Estudo com o Coeficiente Alfa de Cronbach. Produto \& Produção, vol. 11, n. 2, p. 85 - 103, jun. 2010 MORGAN, J. M.; LIKER, J. K. Sistema Toyota de Desenvolvimento de Produto: Integrando Pessoas, Processo e Tecnologia. Porto Alegre: Bookman, 2008.

NETO, Lira. Getúlio. 1030 - 1945 - Do governo provisório à ditadura do Estado Novo. $1^{\text {a }}$. Ed. São Paulo, Cia das Letras, 2013.

OHNO, Taiichi. O Sistema Toyota de Produção - Além da Produção em Larga Escala. Porto Alegre: Bookman, 1997.

OPRIME, P. Carlos; Et al; Análise da complexidade, estratégias e aprendizagem em projetos de melhoria contínua: estudos de caso em empresas brasileiras. Revista Gestão e Produção, vol. 17, São Carlos, 2010.

PACHECO, D. A. de Jesus - Balanceamento de fluxo ou balanceamento de capacidade? Análises e proposições sistêmicas. Gestão e Produção, vol 21 n.2, São Carlos, 2014.

PERGHER, I. Discussão teórica sobre o conceito de perdas do Sistema Toyota de Produção: inserindo a lógica do ganho da Teoria das Restrições. Gestão e Produção, vol.18 no.4 São Carlos, 2011.

PINTO, João Paulo. Pensamento Lean: A filosofia das organizações vencedoras. Lisboa Porto, Lidel - Edições Técnicas Ltda. 5a. Ed. 2009.

PIZETA, E. G., 2009. Análise da regulamentação do suprimento de energia elétrica aos 
polos industriais como fator de competitividade. Dissertação apresentada à Escola Politécnica da Universidade de São Paulo para obtenção do grau de Mestre, orientada por Luiz Natal Rossi, São Paulo, 2009.

ROBBINS, Stephen P. Comportamento organizacional. 9a Ed. São Paulo: Prentice Hal, 2002

RODRIGUES, W. C. Metodologia Cientifica. Paracambi: Apostilha, 2007.

ROSA, Joel M. Correa - Teste de Hipotese - 2011. Disponível em: <http://www.professores.uff.br/joel/lib/exe/fetch.php?media=disciplinas:testehipoteses_beamer.pdf $>$ Acesso: 23 Dez. 2014.

SAVOIA, R. O Gerenciamento do planejamento de mercado nas distribuidoras de energia elétrica: do racionamento ao ambiente regulado e livre de contratação de energia. Dissertação apresentada à Universidade de São Paulo para obtenção do grau de Mestre, orientada por Marcelo Celio Bermann, São Paulo, 2009.

SAURIN, T.A. Et al. Identificação de oportunidade de pesquisa a partir de um levantamento da PE em empresas no Brasil e exterior. Gestão e Produção, vol 17. São Carlos, 2010.

SELLITO et. al., Assessing the degree of promptness of a service industry to adopt lean thinking, REAd, 9(6), 105-130, 2003.

SHIKAMURA S.E. Laboratório de Estatística e Geoinformação. Curitiba: UFPR, 2005.

SILVA, E. S. - Geração de valor no contexto da estratégia de manufatura: uma análise em manufaturas calçadistas. Revista Produção Online, Florianópolis, SC, v.15, n. 1. 2015. SOUTO, R. S. - Aplicação de princípios e conceitos do STP em uma etapa construtiva da construção civil. Dissertação de Mestrado. UFRS, Porto Alegre, 2000.

SOUZA, A. M. Analises de variância. Apostila UFSM, 2015. <Disponivel em: https://docplayer.com.br/18676264-Analise-de-variancia-anova-prof-adriano-mendonca-souza-dr-de-

partamento-de-estatistica-ppgemq-ppgep-ufsm.html> Acesso em: 15.12.2017

SPEAR, S. e BOWEN, H.K. Decoding the DNA of the Toyota Production System. Harvard Business Review, 97-106. 1999.

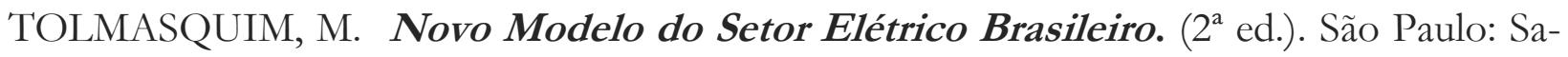
raiva, 2010.

VELA; J. A. Alcalá e OLIVEIRA, A. L. C. Cardoso - Investimentos no Setor Elétrico Brasileiro e a Crise Financeira Mundial. Congresso Brasileiro de Planejamento Energético: Energia 2030: Desafios para uma nova Matriz Energética 08 a 10 de setembro de 2010 São Paulo - SP

VERGARA, Sylvia Constant. Projetos e relatórios de pesquisa em administração. $4^{\mathrm{a}}$. Edição. São Paulo: Editora Atlas, 2003.

VOTTO, R. Goulart,; FERNANDES, F. C. Faria. Produção enxuta e teoria das restrições: proposta de um método para implantação conjunta na Indústria de Bens de Capital sob Encomenda. Revista Gestão e Produção, São Carlos, 2013.

WOLMACK, J.P; JONES, D. T. A Mentalidade enxuta nas empresas: elimine o desperdício e crie riquezas. Rio de Janeiro: Campus, 1996.

WOMACK, James P.; JONES, Daniel T.; ROOS, Daniel. A máquina que mudou o mundo. Rio de Janeiro: Campus, 1998. 